\title{
Silica supported boric tri-sulfuric anhydride as a novel and efficient catalyst for solvent-free synthesis of coumarins via Pechmann condensation
}

\author{
Abolfath Parhami, ${ }^{\text {* }}$ Ali Khalafi-Nezhad, ${ }^{b_{*}}$ Saghar Mowlazadeh Haghighi, ${ }^{\mathrm{b}}$ Rahele \\ Bargebid, ${ }^{\mathrm{b}}$ Abdolkarim Zare, ${ }^{\mathrm{a}}$ and Ahmad Reza Moosavi-Zare, ${ }^{\mathrm{c}}$ and Marzieh Nikrooz ${ }^{\mathrm{a}}$ \\ ${ }^{a}$ Chemistry Department, Payame Noor University,19395-4697 Tehran, I. R. of Iran \\ ${ }^{b}$ Department of Chemistry, College of Sciences, Shiraz University, Shiraz, 71454 Iran \\ ${ }^{c}$ Faculty of Chemistry, Bu-Ali Sina University, Hamedan, 6517838683 Iran

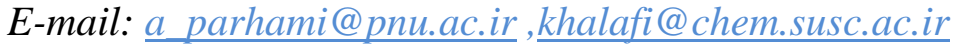

\begin{abstract}
It is found that silica supported boric trisulfuric anhydride $\left(\mathrm{BTSA} \cdot \mathrm{SiO}_{2}\right)$ is a novel, suitable and versatile catalyst for efficient and clean synthesis of coumarins via Pechmann cyclocondensation under mild and solvent-free conditions. Different kinds of phenols and $\beta$-ketoesters were subjected to the cyclization reaction. Particularly, this catalyst makes the condensation of less activated phenols feasible. Besides the described benefits, the reported catalyst was applied successfully for the synthesis of novel coumarins from 3-acetyldihydrofuran-2(3H)-one as well as estradiol (sex hormone).
\end{abstract}

Keywords: Pechmann, coumarins, phenols, $\beta$-ketoesters, boric trisulfuric anhydride (BTSA), solvent-free reactions

\section{Introduction}

Coumarins occupy an important place in the realm of natural products and synthetic organic chemistry. They have been used mainly as anticoagulants, ${ }^{1}$ additives in food and cosmetics, ${ }^{2}$ preparation of insecticides, optical brighteners, ${ }^{2,3}$ dispersed fluorescent and laser dyes. ${ }^{4}$ Moreover, they are well-known as constituents of medicinal plants and many exhibits high levels of biological activity. ${ }^{5}$ As representative, polycyclic coumarins such as calanolides, isolated from Calophyllum genus have shown potent anti-HIV (NNRTI) activity. ${ }^{6}$ Vast efforts have been made by chemists for developing different synthetic routes to coumarins ${ }^{7-11}$ which is as apparent evidence indicating their great importance. Among the methods applied, Pechmann reaction is the most widely applied method for synthesizing coumarins as it involves the condensation of phenols with $\beta$-ketoesters in the presence of a variety of acid condensing agents and gives good 
yields of 4-substituted coumarins. ${ }^{12}$ Several acid catalysts have been used in the Pechmann reaction including Lewis, ${ }^{13}$ protic $^{14}$ and solid acids. ${ }^{15}$ The Pechmann reaction has also been carried out using microwave irradiation, ${ }^{16,17}$ sonication $^{18}$ and in ionic liquids ${ }^{19}$ as alternative to conventional methods. However, the problem still remaining is the low conversions obtained for less activated phenols including hindered ones bearing ortho-substituents or phenols with weak electron-donating substituents. Therefore, there is still an urgent need to develop more efficient catalysts for the condensation of such phenols; furthermore, the synthesis of novel biologically active coumarins is highly desirable. Therefore, in view of the great importance of coumarins as well as the mentioned drawbacks, we report silica supported boric tri-sulfuric anhydride (BTSA.SiO ${ }_{2}$ ) as a novel, reusable and efficient catalyst for the synthesis of structurally diverse coumarins via Pechmann condensation in the absence of solvent (Scheme 1).<smiles>[R]c1cc(O)c([R])c([R])c1[R]</smiles><smiles>[R]OC(=O)C([R7])C([R])=O</smiles>

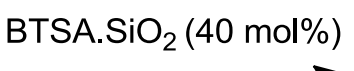

Solvent free $85^{\circ} \mathrm{C}, 1-90 \mathrm{~min}$<smiles>[R]c1c([R])c([R])c2c([R])c([R])c(=O)oc2c1[R]</smiles>

\section{Scheme 1}

\section{Results and Discussion}

To optimize the reaction conditions such as temperature, solvent and amount of catalyst, the reaction of 2-naphthol $(1 \mathrm{mmol})$ with ethyl acetoacetate $(1 \mathrm{mmol})$ was selected as a model. The experiments were carried out employing conventional heating, in the presence of silica supported boric tri-sulfuric anhydride $\left(\mathrm{BTSA}_{\mathrm{SiO}}\right)$ as catalyst, till consumption of the substrates or until no changes in the composition of the reaction mixture were observed. The use of just $40 \mathrm{~mol} \%$ $(0.05 \mathrm{~g})$ of the catalyst could effectively push the reaction forward (70\% yield) at comparatively mild reaction temperature $\left(65^{\circ} \mathrm{C}\right)$ in 60 min under solvent-free conditions.

Our initial experiment focused on the optimization of the reaction temperature. On increasing reaction temperature from 65 up to $95{ }^{\circ} \mathrm{C}$, the product yield and time were found to be more favourable at $85^{\circ} \mathrm{C}$ (Table 1 , entry $\left.1-4\right)$.

Table 1. Effect of Different Temperatures on the Model Reaction

\begin{tabular}{cccc}
\hline Entry & Temperature $\left({ }^{\circ} \mathrm{C}\right)$ & Time $(\min )$ & Yield $^{\mathrm{a}}(\%)$ \\
\hline 1 & 65 & 60 & 70 \\
2 & 75 & 50 & 76 \\
3 & 85 & 45 & 82 \\
4 & 95 & 45 & 80 \\
\hline
\end{tabular}

${ }^{\mathrm{a}}$ Isolated yields. 
Increasing the catalyst up to $80 \mathrm{~mol} \%$ showed no substantial improvement in the yield, though a slight improvement in the reaction time was observed. Therefore, we decided to extend the scope of the reaction using only $40 \mathrm{~mol} \%$ of the catalyst matching benign catalytic processes in which protocols involving lower amounts of catalyst would be more appreciable. Interestingly, no reaction took place in the absence of catalyst for 2 days of reaction time.

Further optimization of the reaction was performed by checking the solvent effect and phenol: $\beta$ ketoester molar ratio. Lower catalytic activity was observed for various organic solvents such as toluene, $\mathrm{MeOH}, \mathrm{CHCl}_{3}, \mathrm{DMF}$ and $\mathrm{MeCN}$ at $85{ }^{\circ} \mathrm{C}$, which is probably due to interference of solvent with active site of the catalyst (Table 2, entry 1-6). On the contrary, the reaction worked well under solvent-free conditions (Table 2, Entry 7).

Table 2. Effect of Different Solvents on the Model Reaction

\begin{tabular}{cccc}
\hline Entry & Solvent & Time (min) & Yield $^{\mathrm{a}}(\%)$ \\
\hline 1 & $\mathrm{PhCH}_{3}$ & 120 & 29 \\
3 & $\mathrm{MeOH}$ & 120 & 50 \\
4 & $\mathrm{CHCl}_{3}$ & 120 & 37 \\
5 & $\mathrm{MeCN}_{6}$ & 120 & 40 \\
6 & $\mathrm{DMF}$ & 120 & 15 \\
7 & No Solvent & 45 & 82 \\
\hline
\end{tabular}

${ }^{\mathrm{a}}$ Isolated yields.

Finally, to determine the best stoichiometric ratio of $\beta$-ketoester to phenol, we performed the reaction of 2-naphthol with ethyl acetoacetate using different molar ratios of $\beta$-ketoester/phenol (Table 3). As Table 3 indicates, the best ratio was $1.2 \mathrm{mmol}$ of $\beta$-ketoester per each mmol of phenol.

Table 3. Effect of Different Amounts of $\beta$-ketoester on the Model Reaction in $45 \mathrm{~min}$

\begin{tabular}{ccc}
\hline Entry & $\beta$-Ketoester/phenol $(\mathrm{mol} / \mathrm{mol})$ & Yield $^{\mathrm{a}}(\%)$ \\
\hline 1 & $0.9 / 1$ & 70 \\
2 & $1.0 / 1$ & 82 \\
3 & $1.1 / 1$ & 87 \\
4 & $1.2 / 1$ & 95 \\
5 & $1.3 / 1$ & 93 \\
6 & $1.5 / 1$ & 89 \\
\hline
\end{tabular}

${ }^{\mathrm{a}}$ Isolated yields.

The results obtained encouraged us to introduce other phenols and $\beta$-ketoesters into the Pechmann reaction using BTSA.SiO 2 . Table 4 shows the reactivity of activated as well as less activated phenolic substrates with different $\beta$-ketoesters using $\mathrm{BTSA}_{\text {. }} \mathrm{SiO}_{2}$ catalyst. 
Table 4. The Solvent-free Pechmann Condensation Between Phenols and $\beta$-Ketoesters Using BTSA.SiO 2

\begin{tabular}{|c|c|c|c|c|c|c|}
\hline Entry & $\beta$-Ketoester & Phenol & Product/Color & $\begin{array}{l}\text { Time } \\
(\min )\end{array}$ & $\begin{array}{c}\text { Yield }^{\mathrm{a}} \\
(\%)\end{array}$ & $\begin{array}{l}\mathrm{Mp},{ }^{\circ} \mathrm{C}^{\mathrm{b}} \\
\text { (lit.) }^{\text {ref. }}\end{array}$ \\
\hline 1 & & & (Light pink) & 45 & 95 & $\begin{array}{c}178-181 \\
(180-182)^{14}\end{array}$ \\
\hline 2 & & & (Light brown) & 17 & 85 & $\begin{array}{c}154-156 \\
(153-155)^{20}\end{array}$ \\
\hline 3 & & $\mathrm{OH}$ & (Light green) & 75 & 90 & $\begin{array}{c}269-270 \\
(271-272)^{21}\end{array}$ \\
\hline 4 & & & (Colorless) & 7 & 98 & $\begin{array}{c}186-188 \\
(184-185)^{20}\end{array}$ \\
\hline 5 & & & (White) & 1 & 99 & $\begin{array}{c}281-283 \\
(280-281)^{20}\end{array}$ \\
\hline 6 & & & (Yellow) & 1 & 89 & $\begin{array}{c}245-247 \\
(243-246)^{20}\end{array}$ \\
\hline
\end{tabular}


Table 4. Continued

\begin{tabular}{|c|c|c|c|c|c|c|}
\hline Entry & $\beta$-Ketoester & Phenol & Product/Color & $\begin{array}{l}\text { Time } \\
(\min )\end{array}$ & $\begin{array}{l}\text { Yield }^{\mathrm{a}} \\
(\%)\end{array}$ & $\begin{array}{c}\mathrm{Mp},{ }^{\circ} \mathrm{C}^{\mathrm{b}} \\
{\text { (lit. })^{\text {ref }}}\end{array}$ \\
\hline 7 & & & (Yellow) & 25 & 90 & $\begin{array}{c}194-196 \\
(195-197)^{20}\end{array}$ \\
\hline 8 & & & (White) & 10 & 90 & $\begin{array}{c}242-243 \\
(245-246)^{22}\end{array}$ \\
\hline 9 & & & $\begin{array}{c}\mathrm{OH} \\
\text { (White) }\end{array}$ & 5 & 90 & $\begin{array}{c}239-241 \\
(243-245)^{23}\end{array}$ \\
\hline 10 & & & & 20 & 90 & 115 \\
\hline 11 & & $\mathrm{OCl}$ & (Colorless) & 90 & 90 & $\begin{array}{c}166-169 \\
(169-170)^{14}\end{array}$ \\
\hline 12 & & & (Colorless) & 75 & 75 & $\begin{array}{c}133-135 \\
(131-133)^{14}\end{array}$ \\
\hline
\end{tabular}


Table 4. Continued

Entry

${ }^{\mathrm{a}}$ Isolated yields. ${ }^{\mathrm{b}}$ All the products are solid.

The reactions were clean and afforded exclusively coumarins in high yields and in relatively short times. A wide range of structurally varied phenols reacted smoothly to give the corresponding coumarins in good yield and purity. The remarkable feature of this improved protocol is the wide stability of a variety of functional groups, such as ether (Table 4, entry 11), homoallylic hydroxyl (Table 4, entries 8-9 and 16-17), and benzyl (Table 4, entry 13) under the present reaction conditions. Moreover, no dehydration occurred in the case of coumarins bearing homoallylic hydroxyl and the products were obtained in high yields and good purity. It is worth 
mentioning that the substrates like cresols which failed to react in many of the protocols reported in the literature, showed moderate reactivity giving satisfactory to excellent yields, under these reaction conditions (Table 4, entries 12 and 14-15).

Different types of $\beta$-ketoesters were used namely, ethyl acetoacetate (Table 4, entries 1-5, 10-15), ethyl benzoylacetate (Table 4, entries 6-7), and 3-acetyldihydrofuran-2(3H)-one (Table 4, entries 8-9 and 16-17). Reactions of phloroglucinol with ethyl acetoacetate, ethyl benzoylacetate and 3-acetyldihydrofuran-2(3H)-one (Table 4, entries 5, 6 and 9) took place very fast within 1, 1 and $5 \mathrm{~min}$, respectively. This is mainly due to the presence of three hydroxyl groups that cooperate in activating the aromatic ring for hydroxyalkylation.

Similarly, reactions of pyrogallol with ethyl benzoylacetate (Table 4, entry 7) took place in $25 \mathrm{~min}$, which are slower than that of the reactions of phloroglucinol presumably due to steric hindrance of hydroxyl groups. The reactions of resorcinol with ethyl acetoacetate, and 3acetyldihydrofuran-2(3H)-one (Table 4, entries 4 and 8) occurred within 7 and $10 \mathrm{~min}$, respectively. This could be due to the presence of only two hydroxyl groups, which are meta to each other. To generalize the protocol we also attempted the condensation reaction using a further variety of phenols such as monohydric and polyhydric naphthols (Table 4, entries 1, 2 and 3), aminophenols (Table 4, entries 16 and 17) and estradiol (Table 4, entry 10) as a phenolic natural product. All these substrates were reacted efficiently and afforded the corresponding products in excellent to satisfactory yields.

The catalyst was also recovered, activated and reused for four consecutive times with only slight variation in the yields of the products. The recovery of the catalyst in each case was $94 \%$. This catalyst was prepared by supporting boric tri-sulfuric anhydride ( 8 meq., $0.87 \mathrm{~g}$, purity $=92.5 \%$ ) on the surface of silicagel $(0.13 \mathrm{~g})$. Boric trisulfuric anhydride $\left(\mathrm{B}\left(\mathrm{OSO}_{3} \mathrm{H}\right)_{3}, \mathrm{MW}=302.02\right.$ $\mathrm{g} / \mathrm{mol}$ ) was prepared according to reported procedure ${ }^{26}$ by gradual addition of chlorosulfonic acid to anhydrous boric acid. In order to calculate the acidic strength of the catalyst we performed the $\mathrm{pH}$-metric titration of the catalyst using aqueous $\mathrm{NaOH}$ solutions with three different concentrations. The titration curves are shown below:

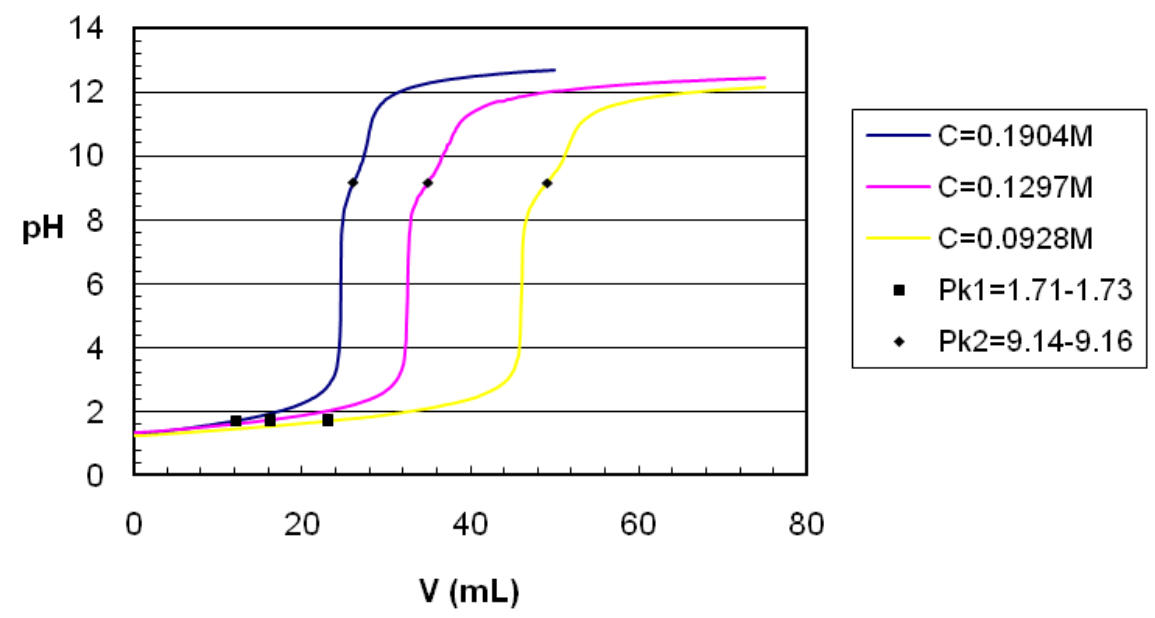

Figure 1. Determination of catalyst Pk values. 
The titration curves showed two distinct endpoints proving the existence of two kinds of acidic sites on the catalyst surface. The first $\mathrm{pK}$ value is $1.71-1.73$ related to $\mathrm{SO}_{3} \mathrm{H}$ groups and the second $\mathrm{pK}$ is 9.14-9.16 which is related to the boric acid impurity in BSA. The acidic capacity of the catalyst was also determined $8.05 \mathrm{mmol} / \mathrm{g}$ related to the stronger acidic functionality.

\section{Conclusions}

In conclusion, BTSA. $\mathrm{SiO}_{2}$ is reported to be an efficient catalyst for the synthesis of coumarins via Pechmann condensation. These conditions are compatible with some acid sensitive functional groups, such as ether, homoallylic hydroxyl and benzyl. This catalyst furnishes facile synthesis of coumarins from less activated phenols including hindered ones bearing ortho substituents or phenols with weak electron donating substituents. Moreover, this method is successfully extended to a wide variety of phenols and $\beta$-ketoesters including ethyl acetoacetate, ethyl benzoyl acetate, 3-acetyldihydrofuran-2(3H)-one, simple phenols and aminophenols as well as estradiol. Furthermore, the catalyst can be easily recovered and reused.

\section{Experimental Section}

General. All novel compounds were characterized by means of spectroscopic methods and known compounds by comparison of their spectral and physical data with those reported in the literature. Infrared spectra were obtained using a Shimadzu FTIR-3800 spectrophotometer. The ${ }^{1} \mathrm{H}-\mathrm{NMR}$ and ${ }^{13} \mathrm{C}-\mathrm{NMR}$ spectra were recorded on a Bruker Avance DPX 250 FT-NMR instrument. Chemical shifts are given in the $\delta$ scale in parts per million (ppm) and the peaks are assigned as singlet $(\mathrm{s})$, doublet $(\mathrm{d})$, triplet $(\mathrm{t})$ and multiplet $(\mathrm{m})$. Elemental analyses were performed on a thermofinnigan flash EA1112-1CHNS. Mass spectra were recorded on a Shimadzu GCMS-QP1000 EX spectrometer. All chemicals were obtained from Fluka or Merck chemical companies. Reaction progress was followed by TLC analysis using silica gel SILG/UV 254 plates.

General procedure for the synthesis of coumarins. To a mixture of phenol $(1 \mathrm{mmol})$ and $\beta$ ketoester or lactone $(1.2 \mathrm{mmol})$ in a $25 \mathrm{~mL}$ round bottomed flask was added $\mathrm{BTSA}_{\mathrm{SiO}}(0.05 \mathrm{~g}$, $40 \mathrm{~mol} \%$ ). Then, the flask was immersed in an oil bath adjusted at $85{ }^{\circ} \mathrm{C}$, equipped with a condenser and the mixture was stirred for suitable period of time indicated in Table 4. After completion of the reaction, the oil bath was removed and the flask was allowed to cool. Afterwards, $50 \mathrm{~mL} \mathrm{CHCl}_{3}$ was added and the suspension was filtered to remove the catalyst. The obtained solution was then washed with water $(2 \times 50 \mathrm{~mL})$ and evaporated. Finally, the residue was recrystalized from ethanol or ethanol-water to obtain the pure compounds. 


\section{Spectral data for novel compounds: ${ }^{27}$ Estradiol coumarin (entry 10).}

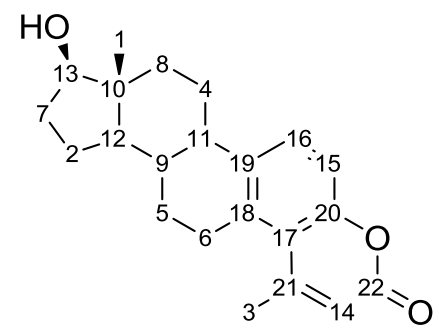

White solid. mp $115{ }^{\circ} \mathrm{C} .{ }^{1} \mathrm{H}$ NMR $\left(250 \mathrm{MHz}\right.$, DMSO- $\left.d_{6}\right): 0.63\left(\mathrm{~s}, 4 \mathrm{H}, \mathrm{CH}_{3}+\mathrm{OH}\right), 1.04(\mathrm{~m}, 1 \mathrm{H})$, $1.07(\mathrm{~m}, 1 \mathrm{H}), 1.17(\mathrm{~m}, 2 \mathrm{H}), 1.24(\mathrm{~m}, 2 \mathrm{H}), 1.28(\mathrm{~m}, 1 \mathrm{H}), 1.52(\mathrm{~m}, 1 \mathrm{H}), 1.78(\mathrm{~m}, 1 \mathrm{H}), 1.83(\mathrm{~m}$, 1H), $2.02(\mathrm{~m}, 1 \mathrm{H}), 2.16(\mathrm{~m}, 1 \mathrm{H}), 2.46(\mathrm{~m}, 1 \mathrm{H}), 2.54(\mathrm{~s}, 3 \mathrm{H}), 2.66(2 \mathrm{H}, \mathrm{t}, J 6 \mathrm{~Hz}), 3.49(\mathrm{t}, 1 \mathrm{H}, J$ $8.5 \mathrm{~Hz}), 6.40(\mathrm{~s}, 1 \mathrm{H}), 6.45(\mathrm{~d}, 1 \mathrm{H}, J 8.5 \mathrm{~Hz}) .{ }^{13} \mathrm{C}$ NMR $\left(62.5 \mathrm{MHz}, \mathrm{DMSO}-d_{6}\right): 11.2(1), 17.9$ (2), 22.71 (3), 26.02 (4), 26.88 (5), 29.09 (6), 29.83 (7), 36.52 (8), 38.63 (9), 42.75 (10), 43.47 (11), 49.46 (12), 79.99 (13), 112.64 (14), 114.84 (15), 125.97 (16), 130.37 (17), 136 (18), 137.07 (19), 148 (20), 154.81 (21), 161 (22). IR (KBr): 3450 (br), 3193 (w), 2912 (m), 2854 (w), 1726 (s), $1569(\mathrm{w}), 1506(\mathrm{~m}), 1278(\mathrm{~m}), 1232(\mathrm{w}), 1160(\mathrm{~m}), 877$ (w), $819(\mathrm{~m})$. Anal. Calc. for $\mathrm{C}_{22} \mathrm{H}_{26} \mathrm{O}_{3}: \mathrm{C}$ 78.07; H 7.74; O 14.18, found: C 78.06; H 7.62. m/e: 338.19 (100.0\%), 339.19 (24.2\%), $340.19(3.3 \%)$.

\section{6-Benzyl-4-methyl-2H-chromen-2-one (entry 13)}

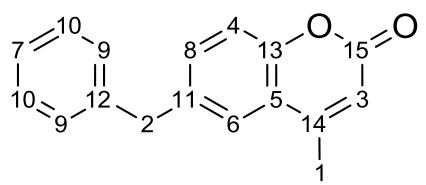

White solid. mp 107-109 ${ }^{\circ} \mathrm{C} .{ }^{1} \mathrm{H}$ NMR (250 MHz, DMSO- $\left.d_{6}\right): 2.29$ (s, 3H), 3.9 (s, 2H), 6.17 (s, 1H), 7.07-7.31 (m, 8H, aromatic). ${ }^{13} \mathrm{C}$ NMR (62.5 MHz, DMSO- $\left.d_{6}\right)$ : 18.6 (1), 41.3 (2), 111.8 (3), 115.1 (4), 117.1 (5), 119.8 (6), 124.5 (7), 126.4 (8), 128.7 (9), 132.5 (10), 137.2 (11), 140.3 (12), 152.03 (13), 152.4 (14), 160.9 (15). IR (KBr): 2941 (w), 2864 (w), 1706 (s), 1610 (m), 1562 (m), 1479 (w), 1373 (m), 1263 (m), 1190 (m), 1064 (w). Anal. Calc. for $\mathrm{C}_{17} \mathrm{H}_{14} \mathrm{O}_{2}$ : C 81.58; H 5.46; O 12.78, found: C 81.13; H 5.59. m/e: 250.10 (100.0\%), 251.10 (18.5\%), 252.11 (1.6\%).

\section{6-Amino-3-(2-hydroxyethyl)-4-methyl-2H-chromen-2-one (entry 16)}

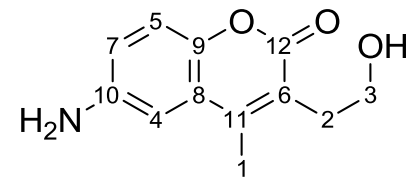

Light brown solid. mp 213-215 ${ }^{\circ} \mathrm{C} .{ }^{1} \mathrm{H}$ NMR (250 MHz, DMSO-d $)$ ): 2.14 (s, 3H), 2.67 (br, 1H), $2.80(\mathrm{t}, 2 \mathrm{H}, J 7.5 \mathrm{~Hz}), 4.1(\mathrm{t}, 2 \mathrm{H}, J 7.5 \mathrm{~Hz}), 4.23(\mathrm{~s}, 2 \mathrm{H}), 6.73(\mathrm{~d}, 1 \mathrm{H}, J 6.25 \mathrm{~Hz}), 6.93(\mathrm{~d}, 1 \mathrm{H} J$ 
$6.25 \mathrm{~Hz}), 8.00(\mathrm{~s}, 1 \mathrm{H}) .{ }^{13} \mathrm{C}$ NMR $\left(62.5 \mathrm{MHz}, \mathrm{DMSO}-d_{6}\right): 14.2 ; 29.74 ; 62.9 ; 115.17 ; 126.06$; 127.28; 129.89; 130.35; 153.11; 154.54; 154.59; 172.10. IR (KBr): 3445 (s), 3360 (s), 3178 (br), 2923 (w), 2869 (w), 1867 (w), 1658 (s), 1581 (m), 1434 (m), 1365 (m), 1242 (s), 1126 (m), 1018 (m), $964(\mathrm{~m}), 825(\mathrm{~m}), 756(\mathrm{w}), 702(\mathrm{w}), 516(\mathrm{~m})$. Anal. Calc. for $\mathrm{C}_{12} \mathrm{H}_{13} \mathrm{NO}_{3}$ : C 65.74; H 5.98; N 6.39; O 21.89, found: C 66.08; H 6.00; N 6.79. m/e: 219.09 (100.0\%).

\section{7-amino-3-(2-hydroxyethyl)-4-methyl-2H-chromen-2-one (entry 17)}

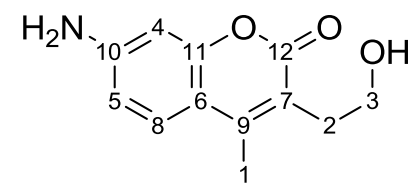

Light yellow solid. $\mathrm{mp}=195-197{ }^{\circ} \mathrm{C} .{ }^{1} \mathrm{H}$ NMR $\left(250 \mathrm{MHz}, \mathrm{DMSO}-d_{6}\right): 2.29(\mathrm{~s}, 3 \mathrm{H}), 2.48$ (br, $1 \mathrm{H}), 2.83(\mathrm{t}, 2 \mathrm{H}, J 7.5 \mathrm{~Hz}), 4.25(\mathrm{t}, 2 \mathrm{H}, J 7.5 \mathrm{~Hz}), 6.48(\mathrm{~m}, 3 \mathrm{H}), 7.1(\mathrm{~m}, 1 \mathrm{H}), 8.13(\mathrm{~s}, 1 \mathrm{H}) .{ }^{13} \mathrm{C}$ NMR $\left(62.5 \mathrm{MHz}\right.$, DMSO- $\left.d_{6}\right): 14.86 ; 27.05 ; 66.87 ; 101.09 ; 111.11 ; 111.30 ; 114.98 ; 129.27$; 140.41; 151.44; 158.00; 173.02. IR (KBr): 3420 (br), 3201 (s), 3193 (m), 2862 (w), 1658 (s), $1484(\mathrm{~m}), 1380$ (s), 1264 (m), 1018 (m), 979 (m), 910 (w), 856 (w), 763 (m), $694(\mathrm{~m}), 632(\mathrm{w})$, 532 (w). Anal. Calc. for $\mathrm{C}_{12} \mathrm{H}_{13} \mathrm{NO}_{3}$ : C 65.74; H 5.98; N 6.39; O 21.89, found: C 65.18; H 6.00; N 6.30. $\mathrm{m} / \mathrm{z}: 219.09(100.0 \%)$.

\section{Acknowledgements}

We acknowledge Payame Noor University (PNU) and Shiraz University research councils for partial support of this work.

\section{References and Notes}

1. Singer, L. A.; Kong, N. P. J. Am. Chem. Soc. 1966, 88, 5213.

2. O'Kennedy, R.; Thornes, R. D. Coumarins: Biology, Applications and mode of action; John Wiley \& Sons: Chichester, 1997.

3. Zahradnik, M. The Production and Application of Fluorescent Brightening Agents; John Wiley \& Sons: New York, 1982.

4. Maeda, M. Laser Dyes, Academic Press, New York, 1984.

5. Pengelly, A. The Constituents of Medicinal Plants, $2^{\text {nd }}$ Ed. Allen\&Unwin: Sydney, 2004.

6. Creagh, T.; Ruckle, J. L.; Tolbert, D. T.; Giltner, J.; Eiznhamer, D. A.; Dutta, B.; Flavin, M. T.; Xu, Z.-Q. Antimicrobial Agents and Chemotherapy 2001, 45, 1379.

7. Pechmann, H. V; Duisberg, C. Chem. Ber. 1883, 16, 2119.

8. Johnson, J. R. Org. React. 1942, 1, 210. 
9. Jones, G. Org. React. 1967, 15, 204.

10. Brufola, G.; Fringuelli, F.; Piermatti, O.; Pizzo, F. Heterocycles 1996, 43, 1257.

11. Shringer, R. L Org. React. 1942, $1,1$.

12. Sethna, S.; Phadke, R. Org. React. 1953, 7, 1.

13. Rajitha, B.; Naveen Kumar, V.; Someshwar, P.; Venu Madhav, J.; Narsimha Reddy, P.; Thirupathi Reddy, Y. Arkivoc 2006, (xii), 23.

14. Shirini, F.; Zolfigol, M. A.; Albadi, J.; J. Iran. Chem. Soc. 2010, 7, 895.

15. Bennardi, D. O.; Ruiz, D. M.; Romanelli, G. P.; Baronettic, G. T.; Thomas, H. J.; Autino, Juan C. Lett. Org. Chem. 2008, 5, 607.

16. Singh, V.; Singh, J.; Kaur, K. P.; Kad, G. L. J. Chem. Research (S) 1997, 58.

17. Frere, S.; Thiery, V.; Besson, T. Tetrahedron Lett. 2001, 42, 2791.

18. Puri, S.; Kaur, B.; Parmar, A.; Kumar, H. Ultrason. Sonochem. 2009, 16, 705.

19. Soares, V. C. D.; Alves, M. B.; Souza, E. R.; Pinto, I. O.; Rubim, J. C.; Andrade, C. K. Z.; Suarez. P. A. Z. Int. J. Mol. Sci. 2007, 8, 392.

20. Sharma, G. V. M.; Reddy, J. J.; Lakshmi, P. S.; Krishna, P. R. Tetrahedron Lett. 2005, 46, 6119.

21. Adam, W.; Qian, X.; Saha-Moeller, C. R. J. Org. Chem. 1993, 58, 3769.

22. Noldner, M.; Chatterjee, S. S.; Hauer, H. U.S.Patent 1996, 5550129.

23. Yang, J. H.; Li, Y. F.; Ji, C. B.; Jiang, S. Z.; Liu, W. Y. Chin. Chem. Lett. 2010, 21, 1165.

24. Osborne, A. G. Tetrahedron 1981, 37, 2021.

25. Al-bayati, R. I. H.; Ayoub, M. T.; Al-hamdany, R. J. Iraqi Chem. Soc. 1985, 10, 141.

26. Kiasat, A. R.; Fallah-Mehrjardi, M. J. Braz. Chem. Soc. 2008, 19, 1595.

27. ${ }^{13} \mathrm{C}-\mathrm{NMR}$ assignations are determined using Cambridgesoft ChemBioDraw Ultra version 11.0.1. 